\title{
Tests of double-strand gap repair as a major source of meiotic gene conversion in fungi
}

\section{B. C. Lamb}

Department of Pure and Applied Biology, Imperial College, London SW7 2BB, U.K.

In current recombination theory, meiotic gene conversions may arise from hybrid-DNA (hDNA), often with correction of mispaired or unpaired bases, or from repair of double-strand gaps. The two types of model have quite different predictions for:- the occurrence and proportions of different classes of aberrant segregations; relationships between conversion properties and the molecular origin of a mutation; the extent of disparity in conversion direction; and whether a heterozygous mutation can affect the conversion properties of other nearby heterozygous mutations. These criteria are used to study the origin of meiotic gene conversions in the fungi Ascobolus, Sordaria and Saccharomyces. Novel tests are described, one based on comparisons of observed conversion frequencies for very close sites within a locus, and one based on possible correlations of $6: 2 / 2: 6$ disparity with the proportion of aberrant segregations having postmeiotic segregation. From Ascobolus, Sordaria and yeast, most data are consistent with most or all meiotic conversions coming from hDNA; they are not consistent with all or most conversions arising directly from doublestrand gap repair. Differences in frequencies of postmeiotic segregation between fungi with four-spored asci and ones with eight-spored asci may reflect a shorter period for hDNA correction in the latter type.

\section{INTRODUCTION}

Many models have been proposed to explain meiotic gene conversion, a term used here to include the production in meiotic octads or tetrads of $5: 3(+: m)$ and $3: 5$ aberrant segregation ratios as well as $6: 2$ and $2: 6 \mathrm{~s}$. In addition to hybrid-DNA (hDNA) models, there is the double-strand gap repair model of Szostak et al. (1983) and OrrWeaver and Szostak (1985), who reviewed current recombination models of both types. On the latter model, gene conversion can come from either repair of double-strand gaps or from hDNA regions flanking the repaired gaps.

As noted by Szostak et al. (1983), the repair of double-strand gaps, on this model, does not produce $5: 3 \mathrm{~s}, 3: 5 \mathrm{~s}$, aberrant $4: 4 \mathrm{~s}$ or correction $4: 4 \mathrm{~s}$; only $6: 2 \mathrm{~s}$ and $2: 6 \mathrm{~s}$ are produced, probably in equal proportions. Within a length of gap repair, there should normally be no effect of mutational type on conversion properties, and one heterozygous mutation should not normally influence properties of nearby sites. By using such features, one can predict the properties of gene conversion in four main situations: (a) conversion almost exclusively from double-strand gap repair; (b) conversion mainly from gap repair, but sometimes from hDNA; (c) conversion sometimes from gap repair but mainly from hDNA; (d) conversion almost exclusively from hDNA. In all cases, even (d), double-strand gaps could initiate gene conversion processes: what is being tested is whether actual conversions arise largely from gap repair regions or from hDNA regions, not what the initiating mechanism for cycles of recombination events is. Szostak et al. (1983, p. 30) assume that situation (b) applies in yeast, and that situation (c) applies in Ascobolus.

The present work examines ways of testing which of situations (a) to (d) applies in particular fungi; it includes two novel methods, one based on comparisons of observed conversion frequencies for very close sites within a locus, and one based on correlations of $6: 2 / 2: 6$ disparity with the proportion of postmeiotic segregations amongst all aberrant segregations. For most of these methods, there are adequate data available for testing conversion origins in particular fungi; where data are insufficient, this work shows what further data are required. Some Ascobolus data have already been shown to be inconsistent with predictions of the double-strand gap repair model, 
such as the different degrees of association of reciprocal crossing-over with different aberrant segregation classes (Rossignol et al. 1984). The relevant issues of "restoration" and "conversion" corrections were analysed by Hastings (1984).

\section{METHODS}

\section{General conversion properties}

Some expected properties of double-strand gap repair and hybrid-DNA models are given in table 1; their presence or absence, or degree of presence, constitute straightforward tests for the origins of gene conversion in any suitable organism. These criteria alone can be sufficient for eliminating some possibilities: e.g., the presence of appreciable proportions of $5: 3,3: 5$, aberrant $4: 4$ or correction 4:4 segregations is sufficient to exclude situation (a), in which conversions arise almost exclusively from double-strand gap repair. High proportions of those classes amongst all aberrant segregations can rule out situation (b), but it is more difficult to discriminate between (c) and (d). Some features, such as polarity in conversion frequencies across a locus, and associations of crossing-over with gene conversion, can occur on gap repair or hDNA models, so will not be considered further.

\section{Use of detected conversion frequencies for very close sites within a gene}

Although correction $4: 4 \mathrm{~s}$ (having had hDNA at the site, but with correction giving the normal $4: 4$ pattern) are not usually detectable, their presence or absence--even when they are not distinguishable from normal $4: 4 \mathrm{~s}$-forms the basis of a new method of distinguishing between conversion arising from gap repair or from hDNA. Closelylinked sites within a locus generally have very similar basic frequencies of conversion events (Paquette and Rossignol, 1978; Kitani and Whitehouse, 1974; Kitani, 1982), which could either result from very similar frequencies of hDNA or from being included in gap repair regions with very similar frequencies, or from equal frequencies of some mixture of the two types of event. This is consistent with current ideas of initiation of recombination on either gap repair or hDNA models, with initiation events giving gaps or hDNA lengths over a series of sites. For very close sites within a locus, with very similar frequencies of inclusion in a gapped region, their observed conversion frequencies (coming from $6: 2$ and $2: 6$ segregations) from gap repair should also be very similar, except for chance sampling variation. For very close sites, with very similar frequencies of inclusion in a hDNA region, their observed conversion frequencies (from $6: 2,2: 6,5: 3,3: 5$ and aberrant $4: 4$ segregations) could be very similar or could differ, sometimes widely, because of different frequencies of undetected correction $4: 4$ segregations.

A difference in correction properties for different heterozygous sites in hDNA can easily give different frequencies of detected conversion even if the sites had exactly the same frequency of hDNA formed. Table 2 (a)-(c), shows how this could occur whether hDNA is all symmetric, or symmetric and asymmetric, or is all asymmetric. Calculation methods and parameter definitions are given in footnotes to table 2 . With all hDNA sym-

Table 1 Some predicted differences between double-strand gap repair and hybrid-DNA models in meiotic conversion properties

\begin{tabular}{|c|c|c|c|}
\hline \multirow[b]{2}{*}{$\begin{array}{l}\text { Criterion } \\
\text { No. }\end{array}$} & \multirow[b]{2}{*}{ Criterion } & \multicolumn{2}{|c|}{ Conversion entirely from: } \\
\hline & & $\begin{array}{l}\text { double-strand } \\
\text { gap repair }\end{array}$ & hybrid-DNA \\
\hline 1 & $5: 3$ and $3: 5$ ratios possible & No & Yes* \\
\hline 2 & Single-event aberrant $4: 4$ segregations possible & No & Yes (from symmetric hDNA only)* \\
\hline 3 & Correction $4: 4$ segregations possible & No & $\begin{array}{l}\text { Yes (from symmetric or asym- } \\
\text { metric hDNA)* }\end{array}$ \\
\hline 4 & $\begin{array}{l}\text { A nearby heterozygous site can affect postmeiotic } \\
\text { segregation frequency }\end{array}$ & $\begin{array}{l}\text { No (unless a pause site is } \\
\text { produced) }\end{array}$ & Yes (from co-conversion) ${ }^{*} \ddagger$ \\
\hline 5 & $\begin{array}{l}\text { Conversion properties related to molecular type } \\
\text { of mutation }\end{array}$ & No & $\begin{array}{l}\text { Yes (from different correction } \\
\text { properties) }\end{array}$ \\
\hline 6 & Disparity between $6: 2$ and $2: 6$ ratios possible & No & Yes* \\
\hline 7 & Disparity between $5: 3$ and $3: 5$ ratios possible & No $5: 3 \mathrm{~s}$ or $3: 5 \mathrm{~s}$ expected & Yes* \\
\hline
\end{tabular}

\footnotetext{
* Frequency or extent will depend on correction properties of the mispair or non-pair in hDNA.

$\dagger$ Excluding double events of 5:3+3:5 (see Lamb and Wickramaratne, 1973).

$\$$ Co-conversion frequencies depend, inversely, on the distance apart of the sites.
} 
metric (table 2(a)) for 10 data sets, all with the same frequency of hDNA $(\gamma)$ of $0 \cdot 300$, the different correction parameter values for those sets gave detectable conversion frequencies ranging from $0 \cdot 162$ to $0 \cdot 283$, because undetected correction $4: 4$ frequencies varied from 0.138 to 0.017 . With a mixture of symmetric and asymmetric hDNA (table 2(b)), detectable conversion frequencies ranged from 0.134 to 0.280 for $\gamma=0.300$, and similar variations were observed when other values of $\alpha, \beta$ and $\delta$ were tried. With all hDNA formed asymmetrically (table $2(\mathrm{c})$ ), detectable conversion frequencies ranged from 0.116 to 0.284 for $\gamma=$ $0 \cdot 300$.

Table 2 The production of different detected conversion frequencies from the same hydrid-DNA frequency, $0 \cdot 300$, when correction parameter differences give different correction $4: 4$ frequencies

\begin{tabular}{|c|c|c|c|}
\hline \multirow[t]{2}{*}{ Set } & \multicolumn{3}{|c|}{ Correction parameter values } \\
\hline & $p$ & $q$ & $r$ \\
\hline (a) & DNA & netri & $0 \cdot 3, \alpha=0$ \\
\hline 1 & $0 \cdot 2$ & $0 \cdot 7$ & $0 \cdot 7$ \\
\hline 2 & $0 \cdot 8$ & $0 \cdot 8$ & $0 \cdot 7$ \\
\hline 3 & 0.4 & $0 \cdot 3$ & 0.4 \\
\hline 4 & 0.6 & 0.4 & 0.4 \\
\hline 5 & 0.9 & $0 \cdot 8$ & 0.4 \\
\hline 6 & $0 \cdot 6$ & $0 \cdot 7$ & $0 \cdot 5$ \\
\hline 7 & $0 \cdot 7$ & $0 \cdot 8$ & $0 \cdot 1$ \\
\hline 8 & $0 \cdot 4$ & $0 \cdot 2$ & $0 \cdot 9$ \\
\hline 9 & $0 \cdot 8$ & 0.6 & $0 \cdot 6$ \\
\hline 10 & 0.8 & 0.9 & 0.8 \\
\hline
\end{tabular}

$\begin{array}{lll}\begin{array}{l}\text { Correction } \\ 4: 4 \\ \text { frequency }\end{array} & \begin{array}{l}\text { Detected } \\ \text { conversion } \\ \text { frequency }\end{array} & \begin{array}{l}\text { Frequ } \\ 6: 2+2\end{array} \\ & & \\ 0.023 & 0.277 & 0.019 \\ 0.096 & 0.204 & 0.096 \\ 0.017 & 0.283 & 0.019 \\ 0.036 & 0.264 & 0.036 \\ 0.116 & 0.184 & 0.099 \\ 0.063 & 0.237 & 0.063 \\ 0.138 & 0.162 & 0.030 \\ 0.020 & 0.280 & 0.004 \\ 0.086 & 0.214 & 0.058 \\ 0.082 & 0.218 & 0.134\end{array}$

$6: 2 / 2: 6 \quad 5: 3 / 3: 5$ disparity disparity $\$$

$\begin{array}{ll}0.4 & 0.023 \\ 0.5 & 0.096 \\ 0.3 & 0.017 \\ 0.5 & 0.036 \\ 0.7 & 0.116 \\ 0.8 & 0.063 \\ 0.9 & 0.138 \\ 0.1 & 0.020 \\ 0.0 & 0.086 \\ 0.7 & 0.082\end{array}$

$0 \cdot 134$

$\begin{array}{rr}+0.217 & -0.142 \\ +0.400 & +0.200 \\ -0.556 & -0.278 \\ -0.200 & -0.138 \\ +0.217 & -0.015 \\ +0.600 & +0.365 \\ 0.000 & +0.211 \\ 0.000 & +0.364 \\ -1.000 & -0.127 \\ +0.806 & +0.462\end{array}$

(b) $60 \%$ of hDNA formed asymmetrically; $\gamma=0 \cdot 3, \alpha=0 \cdot 6 ; \beta=0.5, \delta=0.1$ for asymmetric hDNA

\begin{tabular}{|c|c|c|c|c|c|c|c|c|}
\hline $11 \quad 0.2$ & $0 \cdot 7$ & 0.7 & 0.4 & 0.042 & $0 \cdot 258$ & 0.056 & -0.339 & +0.147 \\
\hline $0 \cdot 8$ & 0.8 & 0.7 & 0.5 & 0.099 & $0 \cdot 201$ & $0 \cdot 122$ & +0.244 & $+0 \cdot 103$ \\
\hline 0.4 & $0 \cdot 3$ & 0.4 & $0 \cdot 3$ & 0.037 & $0 \cdot 263$ & 0.041 & -0.239 & $-0 \cdot 131$ \\
\hline 0.6 & 0.4 & 0.4 & 0.5 & 0.064 & 0.236 & 0.055 & -0.020 & $-0 \cdot 151$ \\
\hline 0.9 & 0.8 & 0.4 & $0 \cdot 7$ & $0 \cdot 141$ & $0 \cdot 159$ & 0.098 & $+0 \cdot 189$ & -0.132 \\
\hline 0.6 & 0.7 & 0.5 & 0.8 & 0.099 & $0 \cdot 201$ & 0.069 & +0.444 & +0.231 \\
\hline 0.7 & 0.8 & $0 \cdot 1$ & 0.9 & $0 \cdot 166$ & $0 \cdot 134$ & 0.036 & 0.000 & +0.185 \\
\hline 0.4 & $0 \cdot 2$ & 0.9 & $0 \cdot 1$ & 0.020 & $0 \cdot 280$ & 0.004 & 0.000 & +0.348 \\
\hline 0.8 & 0.4 & 0.6 & 0.7 & 0.072 & $0 \cdot 228$ & 0.075 & +0.539 & -0.097 \\
\hline 0.7 & $0 \cdot 1$ & 0.8 & 0.9 & 0.026 & $0 \cdot 274$ & 0.054 & +0.918 & +0.027 \\
\hline
\end{tabular}

(c) $100 \%$ of hDNA formed asymmetrically; $\gamma=0 \cdot 3 ; \alpha=1 \cdot 0 ; \beta=0.5, \delta=0 \cdot 1$

\begin{tabular}{|c|c|c|c|c|c|c|c|c|c|}
\hline 21 & $0 \cdot 2$ & 0.7 & 0.7 & 0.4 & 0.053 & $0 \cdot 246$ & 0.081 & -0.428 & +0.364 \\
\hline 22 & 0.8 & 0.8 & 0.7 & 0.5 & $0 \cdot 101$ & 0.199 & 0.139 & +0.244 & +0.103 \\
\hline 23 & 0.4 & 0.3 & 0.4 & $0 \cdot 3$ & 0.050 & $0 \cdot 250$ & 0.055 & $-0 \cdot 164$ & -0.062 \\
\hline 24 & 0.6 & 0.4 & 0.4 & 0.5 & 0.082 & $0 \cdot 218$ & 0.068 & +0.044 & $-0 \cdot 160$ \\
\hline 25 & 0.9 & 0.8 & 0.4 & 0.7 & $0 \cdot 158$ & $0 \cdot 143$ & 0.098 & +0.169 & -0.267 \\
\hline 26 & 0.6 & 0.7 & 0.5 & $0 \cdot 8$ & $0 \cdot 123$ & 0.177 & 0.072 & +0.353 & +0.114 \\
\hline 27 & $0 \cdot 7$ & 0.8 & $0 \cdot 1$ & 0.9 & $0 \cdot 185$ & $0 \cdot 116$ & 0.041 & 0.000 & $+0 \cdot 160$ \\
\hline 28 & 0.4 & $0 \cdot 2$ & 0.9 & $0 \cdot 1$ & 0.016 & 0.284 & 0.074 & +0.325 & -0.114 \\
\hline 29 & 0.8 & 0.4 & 0.6 & 0.7 & 0.090 & $0 \cdot 210$ & 0.090 & +0.533 & -0.400 \\
\hline 30 & 0.7 & $0 \cdot 1$ & 0.8 & 0.9 & 0.040 & $0 \cdot 260$ & 0.080 & +0.914 & -0.400 \\
\hline
\end{tabular}

(d) Double-strand gap frequency of $0 \cdot 300$, with complete repair each time; all conversions from double-strand gap repair, none from hDNA
31
$-\quad-\quad 0.000$
$0 \cdot 300$
$0 \cdot 300$
0.000
No $5: 3 \mathrm{~s}$ or $3: 5 \mathrm{~s}$

\footnotetext{
* The terminology of Kalogeropoulos and Thuriaux (1982) is used. Probabilities at a site are as follows: $\gamma$, formation of hDNA; $\alpha$, asymmetric hDNA; $(1-\alpha)$, symmetric hDNA; $\beta$, recipient chromatid in asymmetric hDNA carried the $m$ allele; $(1-\beta)$, recipient chromatid carried the +allele; $\delta$, invading strand in asymmetric hDNA had $3^{\prime} 5^{\prime}$ polarity; $(1-\delta)$ had $5^{\prime} 3^{\prime}$ polarity. Where $a b$ is the + base pair and $x y$ is the $m$ base pair, there are two possible mis-matches, $a y$ and $x b$; ay has repair probability $p$, with $r$ repaired to,$+(1-r)$ to $m ; x b$ has repair probability $q$, with $s$ repaired to,$+(1-s)$ to $m$. Illustrative values of $p, q, r$ and $s$ were chosen using random numbers with values $0,0 \cdot 1,0.2,0.3, \ldots, 1.0$ for each set, then using those parameter values in equations $1-9$ of Kalogeropoulos and Thuriaux (1982) to obtain expected octad frequencies for $6: 2,2: 6,5: 3,3: 5$ and aberrant $4: 4$ classes.

+Correction $4: 4$ frequencies were calculated from $\gamma \quad(1-\alpha) p q[r(1-s)+(1-r) s]+\gamma \alpha[\beta[\delta q(1-s)+$ $(1-\delta) p(1-r)]+(1-\beta)[\delta p r+(1-\delta) q s]]$.

末 Measured as $(6: 2-2: 6) /(6: 2+2: 6)$; positive values have disparity favouring + ; negative values have disparity favouring $m$. $\S$ Measured as $(5: 3-3: 5) /(5: 3+3: 5)$.
} 
These figures from table 2(a)-(c) show clearly. that different correction parameters for different sites could cause big variations in detected conversion frequencies for any type of hDNA formation. For the sample of 10 values for each condition, the percentages of hDNA formations giving detected conversion ranged from 54 to 94 per cent for symmetric hDNA, from 45 to 93 per cent for a mixture of symmetric and asymmetric hDNA, and from 39 per cent to 95 per cent for asymmetric hDNA. In contrast, a double-strand gap frequency of 0.300 , with complete repair each time, should give a detected conversion frequency of 0.300 for any site, with all gaps giving detected conversion $(6: 2$ and $2: 6$ s only), as in table $2(d)$.

The variations in detectable conversions from close sites with very similar hDNA frequencies are even more noticeable for $6: 2+2: 6$ frequencies than for total conversions in table 2 . From table 2 (a), (b) and (c) respectively, total detected conversion frequencies have means, standard deviations and coefficients of variation of $0 \cdot 239,0 \cdot 042$ and $17 \cdot 5$ per cent; $0 \cdot 227,0 \cdot 046$ and $20 \cdot 3$ per cent; $0.213,0.050$ and $23 \cdot 3$ per cent, while $6: 2+2: 6$ frequencies have means, standard deviations and coefficients of variation of $0.051,0.040$ and 78.8 per cent; $0.060,0.030$ and 49.9 per cent; 0.078 , 0.024 and 31.0 per cent. The difference in variability between the two measures is greatest for symmetric hDNA, least for asymmetric hDNA.

In summary, two or more very close sites within a gene which show more than sampling variation between them in the frequency of detected conversion, and/or in the frequency of $6: 2+2: 6$ segregations, probably have a major proportion of their conversions arising from hDNA, with the differences between them arising from different parameter values for hDNA correction at those sites. If those sites have very similar frequencies of detected conversion and of $6: 2+2: 6$ segregations, then either most conversions arise from double-strand gap repair, or the sites have similar parameter values for hDNA correction. These tests can therefore identify situations (c) or (d) in many cases, if differences are found between close sites, but they can not positively identify situations (a) or (b) if no differences are found. $2 \times n \chi^{2}$ tests can be used to check whether differences are greater than expected from sampling variation. Differences due to environment or background genotype should be eliminated in such experiments.

\section{Use of disparity correlations}

Szostak et al. (1983, p. 30) suggested that in yeast the size of the double-strand gap region is substan- tial, with relatively short flanking regions of hDNA, and that in Ascobolus the gap region is small relative to the amount of hDNA. They also suggested that different frequencies of postmeiotic segregation (p.m.s.) for different yeast sites could be due to different hDNA length/gap length ratios at different sites. As gap repair does not give p.m.s. while hDNA can do so, the measure $(5: 3+$ $3: 5) /(6: 2+2: 6+5: 3+3: 5)$ will partly reflect the hDNA length/gap length ratio, and partly reflect correction properties of hDNA at a site. If proportionately more $6: 2 \mathrm{~s}$ and $2: 6 \mathrm{~s}$ come from gap repair, the value of this expression will decrease, as gap repair does not give $5: 3$ s or $3: 5 \mathrm{~s}$. In addition, accepting the suggestion of Szostak et al. (1983) that gap repair gives no disparity in $6: 2$ and $2: 6$ conversions, an increase in $6: 2 \mathrm{~s}$ and $2: 6 \mathrm{~s}$ from gap repair (compared with $6: 2 \mathrm{~s}$ and $2: 6 \mathrm{~s}$ from hDNA, which may often show disparity) should decrease observed $6: 2 / 2: 6$ disparity. It then follows that as the measure $(5: 3+$ $3: 5) /(6: 2+2: 6+5: 3+3: 5)$ decreases, one expects less $6: 2 / 2: 6$ disparity, though with some scatter because of different correction frequencies at different mismatches. There is no reason, however, why $5: 3 / 3: 5$ disparity should be correlated with this measure. In summary, if the different frequencies of p.m.s. at different sites partly reflect different hDNA length/gap length ratios for those sites, with many conversions coming from gap repair (which increases the denominator in this expression and reduces possible $6: 2 / 2: 6$ disparity) then one expects a positive correlation between absolute values of $6: 2 / 2: 6$ disparity and values of $(5: 3+3: 5) /(6: 2+2: 6+5: 3+3: 5)$, but no correlation between absolute values of $5: 3 / 3: 5$ disparity with the latter ratio. If nearly all conversions came from hDNA, there should be no significant correlation between $6: 2 / 2: 6$ disparity and values of $(5: 3+3: 5) /(6: 2+2: 6+5: 3+3: 5)$.

\section{RESULTS}

\section{General conversion properties}

Table 1 shows the general conversion properties predicted from double-strand gap repair and hDNA models. The extent to which several features of conversion from hDNA are manifested (criteria 1, 2, 3, 4, 6, 7, table 1), such as the relative frequency of postmeiotic classes amongst aberrant segregations, depends greatly on the correction properties of a mutation's mispair or non-pair in hDNA. These correction properties are often related (criterion 5) to the molecular nature of the mutation and/or the mutagen used (Leblon, 1972a, 
b; Lamb and Ghikas, 1979; Yu-Sun, Wickramaratne and Whitehouse, 1977). Some types of mutation are therefore much more suitable than others for testing particular criteria in table 1 . Non-pairs from heterozygous frame-shifts usually have a high frequency of correction, giving relatively low frequencies of $5: 3 \mathrm{~s}$ and $3: 5 \mathrm{~s}$, so basesubstitutions are much better than frame-shifts for testing criterion 1. Base-substitutions are also best for testing criterion 2, while they and frame-shifts can both be used to test criterion 3 . For criterion 4 , the best test is for effects of a heterozygous frame-shift on conversion properties of a nearby base-substitution. For criterion 5, it is best to use a variety of mutagens to produce frame-shift additions and deletions, and base-substitution transversions and transitions.

When the most suitable types of mutation are considered, it is clear that conversion in Ascobolus immersus, Sordaria fimicola and $S$. brevicollis has the properties expected from conversion from hDNA, not from double-strand gap repair. For example, for seven mutations at the $g$ locus in $S$. fimicola, Kitani and Olive (1967, table 3) found frequencies of $5: 3+3: 5$ asci ranging from 41 per cent to 66 per cent of all aberrant segregations, aberrant $4: 4$ s ranging from 13 per cent to 49 per cent, with $6: 2$ and $2: 6$ asci only ranging from 0 per cent to 39 per cent (mean 14 per cent; $\sigma 12$ per cent). No $5: 3 \mathrm{~s}, 3: 5 \mathrm{~s}$ or aberrant $4: 4 \mathrm{~s}$ are expected from double-strand gap repair (table 1, criteria 1 and 2), yet these types together were 60 per cent to 100 per cent of all aberrant segregations, showing that most or all conversions here probably came from hDNA, not from double-strand gap repair, especially as most or all of the $6: 2 \mathrm{~s}$ and $2: 6$ s could have come from hDNA. Similarly, for 15 suitable mutations of the $b_{2}$ locus in $A$. immersus, Rossignol, Paquette and Nicolas (1979, table 1) found frequent $5: 3,3: 5$ and aberrant $4: 4$ segregations, with $6: 2+2: 6 \mathrm{~s}$ ranging from only 6 per cent to 67 per cent (mean $29 \cdot 5$ per cent, $\sigma 19$ per cent), of all aberrant segregations. There are many more examples amongst the data analysed by Lamb (1984). While the average proportions of p.m.s. classes (in relation to other types of aberrant segregation) appear to be lower in yeast than in these filamentous fungi, nine out of 30 sites in yeast data of Fogel et al. (1979) have 10 per cent or more of p.m.s., up to $32,33,41$ and 51 per cent. Hastings (1984) found 85 per cent p.m.s. for his $1-49$ in yeast.

The yeast data underestimate p.m.s. for two reasons. First, table 1 of Fogel et al. (1979) shows that all data for arg 4-4 and arg 4-19 were from heteroallelic crosses (e.g. + , arg 4-19/arg 4-4,+) and much of the data for arg 4-3, arg 4-16 and arg 4-17 were from heteroallelic crosses, in which co-correction can greatly reduce p.m.s. compared to one-point crosses as shown in table 3 . A second cause of underestimation of p.m.s. (especially aberrant $4: 4 s$ ) in yeast, with its four-spored asci, is the greater difficulty in detecting p.m.s. from

Table 3 Values for the frequency of postmeiotic segregations (p.m.s.) amongst aberrant segregations (ab. segs.) at three sites in the $\arg 4$ locus in yeast, in one-, two- and three-point crosses*

\begin{tabular}{|c|c|c|c|c|c|c|c|c|c|}
\hline \multirow[b]{2}{*}{ Cross type } & \multicolumn{3}{|c|}{$\arg 4-19$} & \multicolumn{3}{|c|}{$\arg 4-16$} & \multicolumn{3}{|c|}{$\arg 4-17$} \\
\hline & $\begin{array}{l}\text { p.m.s. } \\
\text { total }\end{array}$ & $\begin{array}{l}\text { ab. segs. } \\
\text { total }\end{array}$ & $\begin{array}{l}\text { p.m.s. as } \\
\text { a } \% \text { of } \\
\text { ab. segs. }\end{array}$ & $\begin{array}{l}\text { p.m.s. } \\
\text { total }\end{array}$ & $\begin{array}{l}\text { ab. segs. } \\
\text { total }\end{array}$ & $\begin{array}{l}\text { p.m.s. as } \\
\text { a } \% \text { of } \\
\text { ab. segs. }\end{array}$ & $\begin{array}{l}\text { p.m.s. } \\
\text { total }\end{array}$ & $\begin{array}{l}\text { ab. segs. } \\
\text { total }\end{array}$ & $\begin{array}{l}\text { p.m.s. as } \\
\text { a \% of } \\
\text { ab. segs. }\end{array}$ \\
\hline One-point & \multicolumn{3}{|c|}{ Data not available } & 231 & 479 & $48 \cdot 2$ & \multicolumn{3}{|c|}{ Data not available } \\
\hline $\begin{array}{l}\text { Two-point: } \\
\text { arg4-19/16 } \\
\text { arg4-16/17 }\end{array}$ & 0 & 31 & 0 & $\begin{array}{l}31 \\
72\end{array}$ & $\begin{array}{l}104 \\
281\end{array}$ & $\begin{array}{l}29 \cdot 8 \\
25 \cdot 6\end{array}$ & 24 & 294 & $8 \cdot 2$ \\
\hline $\begin{array}{l}\text { Three-point: } \\
\arg 4-19 / 16 / 17\end{array}$ & 7 & 104 & $6 \cdot 7$ & 15 & 202 & $7 \cdot 4$ & 3 & 241 & $1 \cdot 2$ \\
\hline $\begin{array}{l}\text { One-, two- } \\
\text { and three- } \\
\text { point values } \\
\text { pooled }\end{array}$ & 8 & 163 & $4 \cdot 9+$ & 388 & 1198 & $32 \cdot 4$ & 58 & 1094 & $5 \cdot 3 \ddagger$ \\
\hline $\begin{array}{l}\text { Two- and } \\
\text { three-point } \\
\text { values pooled }\end{array}$ & 7 & 135 & $5 \cdot 2$ & 118 & 587 & $20 \cdot 1$ & 27 & 535 & $5 \cdot 0$ \\
\hline
\end{tabular}

* Calculated from data in fig. 4 of Fogel et al. (1979). The values in their fig. 2 and table 6 differ slightly because of inclusion of different hybrids.

+ It appears from Fogel et al. (1979), table 1, that all arg4-19 data are from two- or three-point crosses, with no one-point data given.

$\$$ Does include one-point data, but these are not given separately. 
division products of a single yeast ascospore compared with eight-spored asci in Ascobolus and Sordaria, where each sister-spore can be independently isolated and tested for viability and phenotype. Lack of viability of one of the two mitotic products from a yeast ascospore could prevent p.m.s. detection and would go undetected in tests for sectored spore clones. Although Fogel et al. (1979) reported at least 97 per cent efficiency in detecting yeast p.m.s., reconstruction experiments with micro-manipulation together of two unlike, healthy-looking, equal-sized vegetative cells do not accurately reproduce conditions after the first mitosis in a yeast ascospore, where the two products (bud and mother-cell) are initially of very different size.

From Schizosaccharomyces pombe, Thuriaux et al. (1980) reported that most sites had low p.m.s. For nonsense suppressors, in one-point crosses, p.m.s. as a proportion of aberrant segregations were 15 per cent averaged over various sites at sup 3 , sup 8 and sup 9 loci. The average p.m.s. is only $2 \cdot 6$ per cent if the two sites with highest p.m.s. are omitted. Alleles for five other loci had low p.m.s., from small samples.

If fungi with four-spored asci such as $S$. cerevisiae and $S$. pombe generally tend to have less p.m.s. than fungi with eight-spored asci such as Ascobolus and Sordaria, then a simple biological explanation is possible, based on the time available for correction of hDNA to occur in the two types of fungi. In eight-spored asci, the four nuclei from the second meiotic division quickly undergo mitosis (within a few hours in Ascobolus immersus, Worrall and Lamb, unpublished). The DNA replication for that mitosis ends the period in which hDNA correction could occur. In the four-spored asci, correction could continue during ascospore delimitation, differentiation, resting, and even into early germination. Thuriaux et al. (1980) quote $2 \cdot 5$ hours as the time between the onset of ascospore germination and the first mitotic DNA replication round in $S$. pombe. Differences between fungi in average p.m.s. frequencies could therefore reflect different lengths of time available for correction of hDNA, rather than differences in conversion mechanisms.

The ability of one heterozygous site to affect the frequency of postmeiotic segregationcriterion 4, table 1-and also the disparity of a second nearby heterozygous site, was clearly demonstrated in Sordaria fimicola by Kitani and Olive (1969) and in Ascobolus by Leblon and Rossignol (1973). A similar effect was shown in yeast by Fogel et al. (1979), where arg 4-16 had 48 per cent of p.m.s. amongst aberrant segregations when nearby sites were homozygous, but this reduced to 25 per cent, 30 per cent and 7 per cent respectively when $\arg 4-17$, $\arg 4-19$ or both $\arg 4-17$ and $\arg 4-19$ were also heterozygous. Hastings (1984) found a similar effect at the hisl locus in yeast, where his 1-49 had 85 per cent p.m.s. when nearby his $1-1 S$ was $+/+$, but had only 18 per cent p.m.s. if his 1-1S was heterozygous, when nearly all his $1-49$ conversions were actually coconversions with his 1-1S. Thuriaux et al. (1980) showed in $S$. pombe that a site with high p.m.s. in one-point crosses could have reduced p.m.s. in a two-point cross with a nearby mutation having low p.m.s. These impositions of higher correction frequencies of nearby heterozygous sites on a site with less correction (more p.m.s.) is predicted from when conversions arise from hDNA but not from double-strand gap repair. The average frequency of p.m.s. in an organism will also be affected by the frequency of heterozygous cryptic (undetected) mutations, which depends on the strain's history and mating system (Lamb, 1975). Cryptic mutations could increase correction of nearby known mutations by co-correction, hence decreasing p.m.s. at the known site.

Szostak et al. (1983) suggested that the conversion properties in yeast of $\arg 4-16$, with its high frequency of p.m.s., could be explained on the double-strand gap model by assuming that the mutation creates a pause site for a gap-enlargement exonuclease, with adjacent sites having a high probability of inclusion in flanking hDNA. This idea is readily testable using the $\arg 4-16$ data of Fogel et al. (1979), analysed here in table 3. If arg 4-16 acts as a pause site for an exonuclease in a one-point cross, causing it to have high p.m.s., then it should also act as a pause site in two-point or three-point crosses, perhaps retaining most of its high p.m.s. and imposing its pattern of frequent hDNA and high p.m.s. on sites beyond it with respect to the conversion initiation region of the gene. Polarity data (Fogel et al., 1971, fig. 2) suggest the order: centromere, $\arg 4-19, \arg 4-16, \arg 4-17$, arg 4 conversion initiation site. As $\arg 4-19$ and arg 4-17 are separable from arg 4-16 but are close enough to arg 4-16 to co-convert often with it, a comparison of one-, two- and three-point crosses of $\arg 4-16$ constitutes an excellent test of the pause site hypothesis of Szostak et al. (1983, p. 31), from which arg 4-16 should impose its high p.m.s. on $\arg 4-19$ but not on $\arg 4-17$. The data in table 3 show clearly that arg 4-16 does not impose its high frequency of p.m.s. (48 per cent in one-point crosses) on either $\arg 4-19$ or $\arg 4-17$, in two or 
three-point crosses, in which their p.m.s. frequencies are all low, 0 per cent- 8 per cent of all aberrant segregations. These results do not fit the pause site hypothesis, but reduction of p.m.s. frequency for arg4-16 from 48 per cent in one-point crosses to 26-30 per cent in two-point crosses and to only 7 per cent in three-point crosses is exactly as expected if conversion at the $\arg 4$ locus usually arises from hDNA, with co-correction between sites in multi-point crosses. Data on the conversion properties of arg 4-17 and arg 4-19 from one-point crosses would be useful, but are not essential for the above test. Similar data from one- and twopoint crosses were obtained and analysed by Hastings (1984) for the his 1 locus in yeast, where his $1-49$ ( 85 per cent p.m.s. when his $1-1 S$ was $+/+$ ) failed to impose its pattern of high p.m.s. on nearby and frequently co-converting his $1-1 S$, which had no p.m.s. amongst 11 aberrant segregations when his 1-49 was $+/+$, and 1 p.m.s. amongst 13 aberrant segregations when his 1-49 was heterozygous. The reduction of p.m.s. for his 1-49 from 85 per cent to 18 per cent in the heteroallelic cross is as predicted from hDNA models, not from double-strand gap models. While three-point tests, with the high p.m.s. site in the middle, are best for testing the pause site hypothesis, two-point tests can be used if the high p.m.s. site is nearer the recombination initiation end of a predominantly unipolar gene. Hastings (1984) states that his 1-49 and his $1-1 S$ are very close, but does not give their order.

Conversion properties in Ascobolus and Sordaria have been shown often to be clearly related to the molecular nature of the mutation (criterion 5, table 1) and/or to the mutagen used (Leblon, 1972a, b; Lamb and Ghikas, 1979; YuSun, Wickramaratne and Whitehouse, 1977). In yeast the situation is less clear as samples have often been small and are mainly from base-substitutions (see Lamb, 1984, pp. 133-134); more extensive data are needed, especially on frame-shifts and large deletions (see Lamb, 1986, table 4).

Criteria 6 and 7 , table 1 , relate to the presence of parity or disparity in conversion direction, with very frequent and often extreme disparity in Ascobolus and Sordaria (details given by Lamb, 1984, 1986). Szostak et al. (1983, pp. 27 and 30) state that in yeast all classes of mutations and all mutations show parity, with conversion favouring neither the wild-type nor the mutant allele. OrrWeaver and Szostak (1985, p. 36) state that all mutations in the yeast data of Fogel et al. (1979) show approximate parity for $6: 2$ and $2: 6$ segregations. This supposed parity in yeast is a major line of evidence offered in favour of conversions in yeast arising mainly from double-strand gap repair, yet the data from yeast often show significant disparity when suitable sample sizes are analysed. Thus the yeast data of Fogel et al. (1979) actually show significant disparity (at $P=5$ per cent) at 12 out of 30 sites; for some other sites, the sample sizes are too small to show significant differences. Lamb $(1984,1986)$ having analysed several sets of data, concluded that significant disparity is not uncommon in yeast for base substitutions or for large deletions, and that the amount of disparity in yeast was very similar to that in Ascobolus and Sordaria when comparable types of mutations were studied. Some of the yeast data of Fogel et al. (1979) underestimate the disparity which would be found in $+\times m$ crosses as the data for arg 4 mutations came wholly or largely from heteroallelic crosses, sometimes from pooled data from heteroallelic crosses of reversed phase (e.g., arg 4 $16,+/+, 17$ and $16,17 /+,+)$ where co-correction could greatly reduce observed disparities.

\section{Use of detected conversion frequencies for very close sites within a gene}

The theory was given under Methods. If doublestrand gaps are the major source of conversions in a region, very close sites should have very similar detected conversion frequencies, but if most conversions come from hDNA, much more variation in observed conversion frequency and in $6: 2+2: 6$ frequency is expected for close sites within a locus. Variation in observed conversion frequencies for different alleles at a locus ranged from $1 \cdot 2$-fold to 202 -fold for various loci in Ascobolus, yeast and Sordaria (Lamb, 1984), but polarity effects and genetic factors account for much of this variation. There are highly appropriate data for the Ascobolus b2 locus, from Paquette and Rossignol (1978, table 3) when conversion frequency variations between different crosses for the same mutation give an idea of sampling plus genetic background variation, and where their fig. 2 shows the conversion frequency for various $b 2$ sites plotted against position. Conversion frequency (shown here as $\%, \pm$ standard error) differences between the close sites $1 F 1$ $(32.5 \pm 0.28)$ and $F 1(25 \cdot 9 \pm 0 \cdot 30)$, between $1 F 1$ $(32 \cdot 5 \pm 0.28)$ and $8 E(22 \cdot 9 \pm 0 \cdot 23)$, between $8 E$ $(22 \cdot 9 \pm 0 \cdot 23)$ and $17(31 \cdot 7 \pm 0 \cdot 46)$, and between 81 $(15 \cdot 0 \pm 0 \cdot 42)$ and $94(11 \cdot 8 \pm 0 \cdot 30)$, do not appear to be due to polarity effects or sampling variation, but are easily explained by differences in frequencies of correction $4: 4$ asci arising from different 
correction properties for different sites in hDNA. This is consistent with double-strand gaps not being important in Ascobolus. In yeast, the arg 4 locus data of Fogel et al. (1979) show 5.2-fold variation in conversion frequencies for different alleles, and alleles in the cyc1 locus data of Lawrence et al. (1975) show 5.8-fold variation, but the data are not sufficiently extensive to determine the variation's cause as polarity effects or differences in correction 4:4 frequencies. Better data on a well-studied yeast locus are required. For the $g$ locus of $S$. fimicola, Kitani and Olive $(1967$, p. 770$)$ noted even less variation in aberrant segregation frequencies between different alleles when estimated correction $4: 4 \mathrm{~s}$ were included.

\section{Use of disparity correlations}

The theory was given under Methods: results are shown in table 4 . There was no significant positive correlation between $6: 2 / 2: 6$ disparity and the relative frequency of postmeiotic segregations in either Ascobolus or yeast. In yeast, the correlation coefficient of +0.38 is not significantly different from zero. It is similar to the correlation coefficient of +0.33 for $5: 3 / 3: 5$ disparity with the relative frequency of p.m.s., whereas from the double- strand gap repair model one expects the former coefficient to be high and significantly greater than zero, and to be much higher than the latter coefficient. In both tests, absolute disparity values, not signed values, were used, as the magnitude, not the direction, of disparity is important here. In yeast there was no significant correlation of $6: 2 / 2: 6$ disparity with $5: 3 / 3: 5$ disparity, though these were significantly correlated in Ascobolus.

\section{DISCUSSION}

The foregoing results, based on seven general conversion properties, the use of detected conversion frequencies for very close sites within genes, and the use of disparity correlations, are all completely consistent with gene conversion in Ascobolus arising entirely from hDNA (situation (d), Introduction). They are contrary to expectations from situation (a) or (b), where conversions are entirely or largely from double-strand gap repair, although situation (c), with most conversions from hDNA and a minority from double-strand gap repair, can not be ruled out. A slightly less extensive range of tests on Sordaria brevicollis and $S$. fimicola gives results inconsistent with (a) or (b), but entirely consistent with (d) or (c).

Table 4 Tests on yeast and Ascobolus data for correlations between disparity and relative frequency of postmeiotic segregation

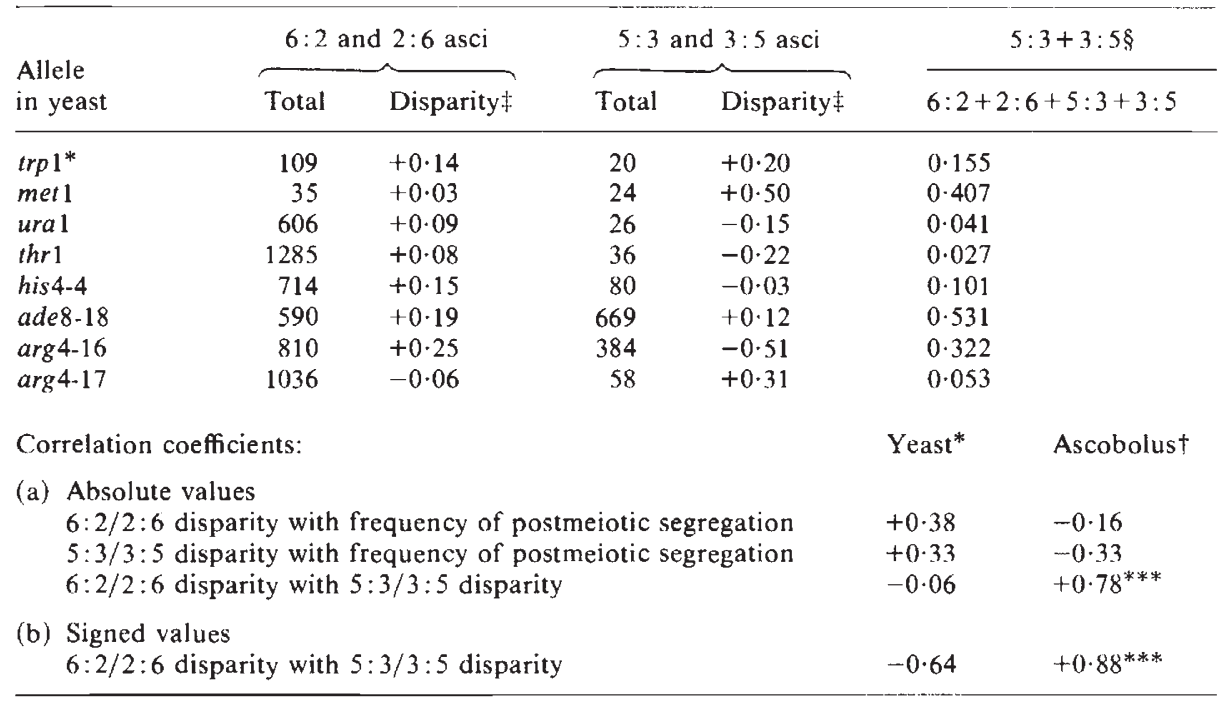

\footnotetext{
* Yeast data of Fogel et al. (1979) table 3, taking all data sets with at least 20 asci of 5:3+3:5 types; smaller numbers give very inaccurate estimates of disparity.

$\dagger$ Ascobolus $b 2$ locus data of Paquette and Rossignol (1978).

$\ddagger$ Disparities calculated as $(6: 2-2: 6) /(6: 2+2: 6)$ and as $(5: 3-3: 5) /(5: 3+3: 5)$; disparity favour ing + gives positive values, disparity favouring $m$ gives negative values.

$\S$ The relative frequency of postmeiotic segregation classes amongst $6: 2,2: 6,5: 3$ and $3: 5$ asci.

*** Significantly different from zero at $P=0 \cdot 1$ per cent; other correlation coefficients were not significantly different from zero at $P=5$ per cent.
} 
The present study shows that many of the yeast results are consistent with most conversions arising from hDNA, for example, because yeast mutations often do have significant disparity in conversion direction, and the pause site hypothesis to explain yeast mutations with frequent p.m.s. is not supported by the $\arg 4-16$ or his 1 data. Virtually all the data are consistent with situation (d), all conversions from hDNA, especially if yeast correction enzymes are often very efficient or have a long period of activity, giving low proportions of p.m.s. for many sites. Some yeast data conflict directly with situations (a) and (b), e.g., some sites having frequent p.m.s. and disparity being frequent.

In conclusion, most data from Ascobolus and Sordaria are consistent with all or most conversions coming from hDNA; they are not consistent with all or most conversions coming from double-strand gap repair. In yeast, most data are also consistent with most conversions coming from hDNA; some of the data are not consistent with all or most conversions coming from double-strand gap repair. When the data are re-examined, some of the previously suggested differences in conversion properties between yeast and filamentous fungi can be shown to be less marked than had been proposed; some can be explained in terms of the multi-point nature of some of the yeast crosses, and others could result from higher correction efficiencies for hDNA in yeast, rather than in different frequencies of conversions arising from hDNA and double-strand gap repair. The tests described here for differentiating between conversions originating from hDNA and from doublestrand gaps could be applied to other organisms in which tetrad or octad analysis is possible.

Acknowledgements I am grateful to S. Zwolinsky for helpful comments on the manuscript.

\section{REFERENCES}

FOGEL, S., HURST, D. D. AND MORTIMER, R. K. 1971. Gene conversion in unselected tetrads from multipoint crosses. In Kimber, G. and Rédei, G. P. (eds.) Stadler Genetics Symposia, vol. 1 and 2, Columbia, pp. 89-110.

FOGEL, S., MORTIMER, R., LUSNAK, K. AND TAVARES, F. 1979. Meiotic gene conversion: a signal of the basic recombination event in yeast. Cold Spring Harb. Symp. Quant. Biol., $43,1325-1342$.

HASTINGS, P. J. 1984. Measurement of restoration and conversion: its meaning for the mismatch repair hypothesis of conversion. Cold Spring Harb. Symp. Quant. Biol., 49, 4953.

Kalogeropoulos, A. AND thuriauX, P. 1982. Parameters in gene conversion. Genet. Res., 40, 1-18.
KITANI, Y. 1982. Characteristics of gene conversion and Rec factor of the $i$ locus of Sordaria fimicola. Jpn. J. Genet., 57, $467-481$.

KITANI, Y. AND OLIVE, L. S. 1967. Genetics of Sordaria fimicola. VI. Gene conversion at the $g$ locus in mutant $\times$ wild type crosses. Genetics, 57, 767-782.

KITANI, Y. AND OLIVE, L. S. 1969. Genetics of Sordaria fimicola. VII. Gene conversion at the $g$ locus in interallelic crosses. Genetics, 62, 23-66.

KITANI, Y. AND WHITEHOUSE, H. L. K. 1974. Aberrant ascus genotypes from crosses involving mutants at the $g$ locus in Sordaria fimicola. Genet. Res., 24, 229-250.

LAMB, B. C. 1975. Cryptic mutations: their predicted biochemical basis, frequencies and effects on gene conversion. Mol. Gen. Genet., 137, 305-314.

LAMB, B. C. 1984. The properties of meiotic gene conversion important in its effects on evolution. Heredity, 53, 113-138.

LAMB, B. C. 1986. Gene conversion disparity: factors influencing its direction and extent, with tests of assumptions and predictions in its evolutionary effects. Genetics, 114, 611-632.

LAMB, B. C. AND GHIKAS, A. 1979. The intergradation, genetic interchangeability and interpretation of gene conversion spectrum types. Genetics, 92, 49-65.

LAMB, B. C. AND WICKRAMARATNE, M. R. T. 1973. Corresponding-site interference, synaptinemal complex structure, and $8+: 0 m$ and $7+: 1 m$ octads from wild-type $\times$ mutant crosses of Ascobolus immersus. Genet. Res., 22, $113-124$.

LAWRENCE, C. W., SHERMAN, F., JACKSON, M. AND GILMORE, R. A. 1975. Mapping and gene conversion studies with the structural gene for iso-1-cytochrome $c$ in yeast. Genetics, $81,615-629$

LEBLON, G. 1972a. Mechanism of gene conversion in Ascobolus immersus. I. Existence of a correlation between the origin of mutants induced by different mutagens and their gene conversion spectrum. Mol. Gen. Genet., 115, 36-48.

LEBLON, G. 1972b. Mechanism of gene conversion in Ascobolus immersus. II. The reiationships between the genetic alterations in $b_{1}$ or $b_{2}$ mutants and their conversion spectrum. Mol. Gen. Genet., 116, 322-335.

LEBLON, G. AND ROSSIGNOL, J-L. 1973. Mechanism of gene conversion in Ascobolus immersus. III. The interaction of heteroalleles in the conversion process. Mol. Gen. Genet., $122,165-182$.

ORR-WEAVER, T. L. AND SZOSTAK, J. W. 1985. Fungal recombination. Microbiol. Rev., 49, 33-58.

PAQUETTE, N. AND ROSSIGNOL, J-L. 1978. Gene conversion spectrum of 15 mutants giving post-meiotic segregation in the $\mathrm{b}_{2}$ locus of Ascobolus immersus. Mol. Gen. Genet., 163, 313-326.

ROSSIGNOL, J-L., NICOLAS, A., HAMZA, H. AND LANGIN, T. 1984. Origins of gene conversion and reciprocal exchange in Ascobolus. Cold Spring Harb. Symp. Quant. Biol., 49, 13-21.

ROSSIGNOL, J-L., PAQUETTE, N. AND NICOLAS, A. 1979. Aberrant $4: 4$ asci, disparity in the direction of conversion, and frequencies of conversion in Ascobolus immersus. Cold Spring Harb. Symp. Quant. Biol., 43, 1343-1352.

SZOSTAK, J. W., ORR-WEAVER, T. L., ROTHSTEIN, R. J. AND STAHL, F. W. 1983. The double-strand-break repair model for recombination. Cell, 33, 25-35.

THURIAUX, P., MINET, M., MUNZ, P., AHMAD, A., ZBAEREN, D. AND LEUPOLD, U. 1980. Gene conversion in nonsense suppressors of Schizosaccharomyces pombe. II. Specific marker effects. Curr. Genet., 1, 89-95.

YU.SUN, C. C. C., WICKRAMARATNE, M. R. T. AND WHITEHOUSE, H. L. K. 1977. Mutagen specificity in conversion pattern in Sordaria brevicollis. Genet. Res., 29, 65-81. 